Bartın Üniversitesi

Eğitim Fakültesi Dergisi

Cilt 6, Sayı 2, s. 676-688, Haziran 2017

BARTIN - TÜRKIYE

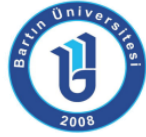

ISSN: 1308-7177
Bartin University

Journal of Faculty of Education

Volume 6, Issue 2, p. 676-688, June 2017

BARTIN - TURKEY

\title{
Proje Tabanlı Öğrenme Sürecinin Ortaokul Öğrencilerinin Akademik Öz-Yeterlikleri ve Motivasyonları Üzerine Etkisinin Incelenmesi*
}

Solmaz AYDIN, Yrd Doç. Dr., Kafkas Üniversitesi Üniversitesi Eğitim Fakültesi, solmazaydn@gmail.com Tazegül DEMIR ATALAY, Doç. Dr., Kafkas Üniversitesi, Eğitim Fakültesi, tazeguldemir@gmail.com Volkan GÖKSU, Yrd Doç. Dr., Kafkas Üniversitesi Üniversitesi Eğitim Fakültesi, volkangoksu36@gmail.com

Öz: Bu çalışmanın amacı, başarılı ve girişken ortaokul öğrencilerine imkân tanıyarak onlara ilgi ve yetenekleri doğrultusunda, kendi projelerini yapabilme ve tanıtabilme olanağı sağlamak ve öğrencilere sunulan bu fırsatın onların akademik öz-yeterliklerine ve akademik motivasyonlarına katkısını belirlemektir. Çalışmada, tek grup ön test-son test deneysel desen kullanılmıştır. Çalışma grubunu Kars il merkezinde bulunan ortaokul öğrencilerinden çalışmaya katılmak isteyen 7. sınıf öğrencileri oluşturmaktadır. TÜBiTAK destekli bu çalışmanın il Milli Eğitim Müdürlüğü aracılığıyla tanıtımı sonrasında 42 öğrenci çalışmaya katılmıştır. Veri toplama aracı olarak, "Akademik ÖzYeterlik Ölçeği" ve "Akademik Motivasyon Ölçeği" kullanılmıştır. Çalışmanın sonucunda, öğrencilerin kendi yeteneklerine ve bulundukları okul ortamlarına yönelik güvenlerinde bir değişme meydana gelmediği belirlenmiştir. Öğrencilerin akademik motivasyon düzeylerine baktığımızda ise özdeşleşmiş dışsal motivasyon, içe yansıtılmış dışsal motivasyon ve motivasyonsuzluk düzeylerinde bir değişme meydana gelmediği tespit edilmiştir. Fakat proje çalışmasına katılan öğrencilerin, proje çalışmaları sonrasında içsel motivasyon düzeylerinde anlamlı bir artış olduğu görülmüştür. Bu durum öğretmenlerin, öğrencilerinin derse karşı içsel olarak motive olmuş bir şekilde katılmalarını sağlamaları için derslerinde proje çalışmaları yapabileceklerini göstermektedir.

Anahtar Kelimeler: Proje Tabanlı Öğrenme, Öz-yeterlik, Motivasyon.

\section{The Effects of Project Based Learning Process on the Academic Self-Efficacy and Motivation of Middle School Students}

Abstract: The aim of this study is to enable successful and enterprising middle school students to be able to make their own projects and introduce them in line with their interests and abilities, and to determine the contribute of this opportunity on their academic self-efficacy and academic motivation. In the study, a single group pre-test-post-test experimental design was used. The working group constitutes 7th grade students who want to participate in the study from the middle school students in Kars province center. After the presentation of this work supported by TÜBITAK through the Provincial Education Directorate (MEB), 42 students participated in the study. "Academic Self-Efficacy Scale" and "Academic Motivation Scale" were used as data collection tools. As a result of the study, it was determined that the students did not change their confidence in their ability and the school environment. When we look at the academic motivation levels of the students, it has been determined that there is no change in the levels of identified external motivation, introjected external motivation and amotivation. However, it was seen that the students who participated in the project study showed a significant increase in the levels of intrinsic motivation after project work. This demonstrates that teachers can do project work in their lessons in order to ensure that their students participate in the lesson motivated internally.

Key Words: Project Based Learning, Self-efficay, Motivation.

\footnotetext{
* Bu çalışma TÜBITAK tarafından desteklenen 114K755 nolu araştırma projesinin bir bölümüdür.
} 


\section{GiRiş}

Günümüz eğitim sisteminde kendi öğrenme sürecini düzenleyebilen ve yapılandırabilen bireyler yetiştirilmeye çalışılmakta, öğrenci merkezli yöntemlerin ağırlıkta olduğu öğretim süreçleri planlanmaktadır. Bu niteliklere uygun öğretim yöntemlerinden biri olan proje tabanlı öğrenmenin günümüzde önemi giderek daha iyi anlaşılmakta ve öğretim programlarında yer almaktadır. Proje tabanlı öğrenme genel olarak bilimsel kavramların, çeşitli bilgi ve becerilerin, tutum ve değerlerin öğretilmesinde kullanılabilen gerçek yaşamda karşılaşılan bazı problemlerin, olayların araştırdığı ve sonuçların sözlü sunum ya da yazılı rapor şeklinde paylaşıldığı aktif bir öğrenme yöntemi olarak tanımlanmaktadır (Krajcik, Czerniak ve Berger, 1999; Thomas, 2000). Bir konudaki eksikliğin ya da problemin ortaya konulması ve çalışmanın sonucunda bir ürün elde edilmesi bu yaklaşımın temel unsurudur.

Proje tabanlı öğrenme ortamında öğrenciler kendi öğrenme süreçlerini yönlendirebilirler, yaratıcılıklarını ve işbirliği içinde problem çözebilme becerilerini geliştirebilirler ve bu yöntemle gerçek yaşam, sınıf içine taşınmış olur (Erdem, 2002). Proje tabanlı öğrenme yaklaşımının öğretim süreci içerisinde kullanılmasının birçok yararı bulunmaktadır. Bunları şu şekilde özetleyebiliriz: Öğrencilerin motivasyonunu ve yaratıcılığını artıır; öğrenmeye karşı tutumlarının, olumlu eğilimlerinin ve öz-yeterlik inançlarının gelişimine katkıda bulunur; problem çözme becerisinin ve bilimsel çalışma alışkanlığının kazanılmasına yardımcı olur, öğrenme ve yaşamsal beceriler kazanmalarına yardımcı olur, işbirliğine dayalı öğrenme becerileri gelişir (Korkmaz ve Kaptan, 2001; Sünbül, 2007). Blumenfeld ve arkadaşları (1991), proje çalışmalarının öğrencilerin çeşitli bilgiler, kavramlar ve ilkeler elde etmelerine yardımcı olduğunu ve öğrenme, üst biliş potansiyellerini artırdığını belirtmiştir. Bunların yanında proje çalışmaları öğrencilerin içsel motivasyonlarını artırmada (Toci, 2000), öğrencilerin derse karşı ilgisini artırmada (Blumenfeld vd,1991; Petersen, 2008), derslerin kalıcılık düzeyini artırmada (Çiftçi, 2006) yararlı olmaktadır. İncelenen literatür göstermektedir $\mathrm{ki}$, proje çalışmaları öğrencilerin kendilerine olan güvenlerine yani yeterlik algılarına ve motivasyonlarına katkıda bulunmaktadır.

Öz-yeterlik, bazı işleri başarmak ve bazı eylemleri yapmak için bireylerin kendi yeteneklerine duydukları güven düzeyi olarak tanımlanmaktadır (Bandura, 1997). Öz-yeterliği güçlü olan kişilerin, karşılaştıkları zorluklarla başa çıkabilme becerileri de güçlü olur (Bandura ve Adams, 1977). Zimmerman (1989), öz-yeterlik algısının öğrencilerin aktivitelere katılımını ve akademik başarısını olumlu bir şekilde etkileyeceğini belirtmiştir. Bu açılardan bakıldığında kendilerine güvenen öğrencilerin proje çalışmalarına daha etkili katılabilecekleri ve daha başarılı ürünler elde edebilecekleri söylenebilir. Schunk ve Meece (2006), öğrenme amaçlarının belirlenmesinin, öğrencilere öğrenme stratejilerini kullanmalarının öğretilmesinin ve performans ve geri bildirime dayalı etkinliklerin yapılmasının öz-düzenlemeyi geliştireceğini belirtmiştir. Dolayısıyla proje tabanlı öğrenme sürecine bakıldığında, öğrencilerin özyeterliklerinin gelişimine katkıda bulunabileceği düşünülmektedir. Nitekim bu konuda yapılan çalışmalar bu düşünceyi destekler niteliktedir (Aydın, 2013; Mills, 2009). Fakat sınırlı sayıda olan bu konudaki çalışmaların genellikle üniversite öğrencisi seviyesinde yapıldığı görülmektedir. Bu nedenle yapılan bu çalışmada ortaokul seviyesinde öğrencilerle çalışıldığından dolayı literatüre katkıda bulunacağı düşünülmektedir. 
Bunun yanında öğrenci motivasyonuna da bakıldığında, motivasyon bir işi yapmak için istek duyarak harekete geçmek şeklinde nitelendirilmektedir(Ryan ve Deci, 2000). Eğitim ortamında motivasyona sahip öğrenciler okula yönelik olumlu düşüncelere sahiptir, zor görevlere karşı çabucak pes etmezler ve daha derinlemesine öğrenirler (Akbaba, 2006). Ayrıca motivasyon akademik başarısıyla da pozitif ilişkilidir (Fortier, Vallerand, ve Guay, 1995; Gottfried, 1990; Tuan, Chin ve Shieh, 2005). Öğrencilerin öğrenmeye karşı motive olmaları onların derse karşı ilgi duymalarını ve daha başarılı olmalarını sağlayacaktır. Bu nedenle eğitim sürecinde öğretmenlerin öğrencilerin motivasyonlarını artıracak etkinlikler yapmaları yararlı olacaktır. Illgili literatüre bakıldığında, proje tabanlı öğrenmenin öğrenci motivasyonunu artırdığı görülmektedir. Helle, Tynjala ve Olkinuora (2006), proje tabanlı öğrenmenin öğrenci motivasyonu üzerinde pozitif bir etkiye sahip olduğunu ifade etmiştir. Blumenfeld ve ark. (1991), uzun vadeli önemli bir problemin çözümüne yönelik ve bir ürünün elde edildiği projelerin öğrencileri motive ettiğini ve konuyu daha iyi anlamalarına yardım ettiğini belirtmişlerdir.

Yukarıda belirtildiği gibi proje tabanlı öğrenmenin bu kadar çok yararının yanında proje çalışmalarının zaman alması, rehberlik ve uzmanlık gerektirmesi gibi bazı sınırlılıkları da bulunmaktadır. Fleming (2000) ve Gerlach (2008) öğrencilerin proje çalışmalarında daha fazla rehberliğe ihtiyaç duyduklarını belirtmişlerdir. Elbette ki bu sınırlılıklar öğretmenler tarafından proje çalışmalarının daha az kullanıımasına yol açabilmektedir. Önen, Mertoğlu, Saka ve Gürdal (2010), 104 öğretmenle yaptıkları çalışmada hizmet içi eğitim öncesinde öğretmenlerin proje çalışmalarını hiç kullanmadıklarını, hizmet içi eğitim sonrası kullanmakta daha istekli olduklarını belirtmişlerdir. Aktepe ve Aktepe (2009), çalışmalarında fen ve teknoloji öğretiminde öğretmenlerin proje çalışmalarını bazen kullandıklarını ve öğrencilerin bu yöntemi her fırsatta kullanmak istediklerini belirtmişlerdir.

Proje çalışmalarına yönelik özetlenen tüm bu araştırmalar göstermiştir ki, proje tabanlı öğrenme yöntemi birçok açıdan yararlı olmuş; fakat yeteri kadar uygulanmamıştır, öğrencilerin öz-yeterlik ve motivasyonlarının etkisine yönelik yeterli çalışma bulunmamaktadır. Bu durum düşünüldüğünde, yapılan bu çalışmayla hem öğrencilere proje çalışmaları yapma imkânı tanınmış, hem de proje çalışmalarının öğrencilerin akademik öz-yeterlikleri ve motivasyonları üzerine etkisi deneysel bir çalışmayla belirlenerek literatüre katkıda bulunulmuştur.

\section{2.ÇALIŞMANIN AMACI}

TÜBITAK tarafından desteklenen bu çalışmanın temel amacı, Kars il merkezinde bulunan başarılı ve girişken ortaokul öğrencilerine imkân tanıyarak onlara ilgi ve yetenekleri doğrultusunda, kendi projelerini yapabilme ve tanıtabilme olanağı sağlamak ve öğrencilere sunulan bu fırsatın onların, akademik öz-yeterliklerine ve akademik motivasyonlarına katkısını belirlemektir.

\section{YÖNTEM}

Bu bölümde araştırmanın modeli, çalışma grubu bilgileri yer almaktadır. 


\subsection{Araştırma Modeli}

Çalışmada, tek grup ön test-son test deneysel desen kullanılmıştır. Bu desende bağımlı değişkene ilişkin elde edilen ölçümler, uygulama öncesinde ön test, sonrasında son test olarak aynı deneklerden aynı ölçme araçları kullanılarak elde edilir (Büyüköztürk vd., 2012).

\section{2. Çalışma Grubu}

Çalışmada öncelikle, ilı Milli Eğitim Müdürlüğü ile işbirliği yapılarak il merkezinde bulunan ortaokul 7. sınıflara çalışma tanıtılmış ve proje tabanlı öğrenme süreci örneklerle anlatılmıştır. Öncelikle proje çalışmasını rahatlıkla yürütebileceği düşünülen ortaokul 7 ve 8 . sınıfların çalışmaya uygun olduğu düşünülmüş, daha sonra ill Milli Eğitim Müdürlüğünün önerisiyle proje çalışma süreci uzun olduğundan ve 8. sınıfların TEOG sınavına hazırlandıklarından dolayı 7. sınıflarla çalışımaya karar verilmiştir.

Öğrencilere yapılan tanıtımdan sonra proje çalışmalarına gönüllü olan öğrenciler, ilgi duydukları alanlara yönlendirilerek Fen, Türkçe ve Sosyal bilimler alanlarında proje gruplarına katılmaları sağlanmıştır. Kafkas Üniversitesinde yürütülecek olan bu çalışmada, belirlenen üç alanda yeterli öğretim üyesi bulunması nedeniyle ilgili alanlarda proje çalışmaları yapılmıştır. Tanıtım çalışması sonrasında toplam 47 öğrenci gruplara ayrılarak proje çalışmalarına başlamış; fakat ilk hafta sonrasında beş öğrenci ayrılmış ve 42 öğrenci ile proje çalışmalar tamamlanmıştır.

\subsection{Veri Toplama Araçları}

Çalışmada kullanılacak veri toplama araçları şunlardır:

\section{Akademik Öz-yeterlik Ölçeği (AÖYÖ)}

Akademik Öz-Yeterlik Ölçeği, öğrencilerin akademik-eğitsel işlere yönelik öz-yeterliklerini ölçmek amacıyla kullanılacak olan bir ölçektir. Çalışmada Öncü (2012) tarafından ilköğretim 5, 6, 7 ve 8. sınıflar için Türkçeye uyarlanan "Akademik Öz-yeterlik Ölçeği” kullanılmıştır. Ölçek dörtlü likert yapıda ve 21 maddeden oluşmaktadır. Ölçeğin alt boyutları ise "yetenek", "ortam" ve "eğitimin kalitesi" şeklindedir. Ölçeğin Cronbach alfa ve test tekrar test güvenilirlik katsayıları .82 ve $.80^{\prime}$ dir.

AÖYÖ proje çalışması öncesinde, ön test olarak ve sonrasında son test olarak çalışma grubuna uygulanmıştır. Ölçek kullanılmadan önce araştırmanın çalışma grubunun dışında olan 7.sınıf öğrencilerine uygulanarak Doğrulayıcı Faktör analizi (DFA) yapılmıştır.

Örnek Ölçek Maddeleri: "Okulda iyi notlar almak benim için zor değildir", "Sınıf arkadaşlarımın çoğu ev ödevlerine benden daha çok çalışıyor", "Çocukken iyi öğrenci olanlar, yetişkinlikte iyi iş sahibi olabilirler".

\section{Akademik Motivasyon(Güdülenme) Ölçeği (AMÖ)}

Akademik Motivasyon ölçeği öğrencinin akademik-eğitsel işlere yönelik performansınıgüdülenmesini ölçmek amacıyla kullanılacak olan bir ölçektir. Çalışmada Kara (2008) tarafından, ilköğretim 4 ve 5. sınıflar için Türkçeye uyarlanan "Eğitimde Motivasyon Ölçeği" 
kullanılmıştır. Ölçek üçlü likert yapıda ve 12 maddeden oluşmaktadır. Ölçeğin alt boyutları "özdeşleşmiş dışsal motivasyon", "motivasyonsuzluk", "içe yansıtılmış dışsal motivasyon" ve "içsel motivasyon" şeklindedir. Cronbach alfa güvenilirlik katsayısı ise .84'dür.

AMÖ proje çalışması öncesinde ön test olarak ve sonrasında son test olarak çalışma grubuna uygulanmıştır. Ölçek kullanılmadan önce araştırmanın çalışma grubunun dışında olan 7.sınıf öğrencilerine uygulanarak Doğrulayıcı Faktör analizi (DFA) yapılmıştır.

Örnek Ölçek Maddeleri: "Öğretmenlerimin sınıfta anlattıklarını kendi iyiliğim için dinliyorum", "Okula gidiyorum ancak bana ne yarar sağlayacağını bilmiyorum", "Okula gidiyorum çünkü okula gittiğimde mutlu oluyorum".

\section{Deneysel Çalışma Süreci}

1. Çalışma süreci altı aydır. Çalışmalar, eylül ayında başlayıp mayıs ayında öğrenci projelerinin tanıtımının yapııdığı bilim şenliği etkinliğiyle ile tamamlanmıştır.

2. Öncelikle konuyla ilgili hazırlıklar yapılıp, gerekli izinler alınarak öğrencilere çalışma süreci ve proje tabanlı öğrenme konusu örneklerle birlikte araştırmacılar tarafından tanıtılmıştır.

3. Tanıtım sonrası gönüllü olan öğrenciler öğretmenlerinin de desteğiyle proje çalışmalarına katılmaya gönüllü olarak, ilgi duydukları alanlarda çalışma gruplarına katılmışlardır.

4. Öğrenci seçimi esnasında Kafkas Üniversitesi Eğitim Fakültesinde, öğrencilerin proje çalışmalarını yürütebilecekleri bir proje sınıfı oluşturulmuştur. Farklı farklı okullardan gönüllü öğrencilerin projeye katılmaları ortak bir mekan oluşturulması zorunluluğunu beraberinde getirmiştir. Proje sınıfında öğrencilerin kullanabilecekleri bilgisayarlar, yazıcı, kırtasiye malzemeleri ve çay-kahve makinesi bulundurulmuştur. Sınıftaki masalar grup çalışması yapılabilecek şekilde yerleştirilmiştir. Öğrenciler bu sınıfı istedikleri zaman araştırma yapmak ve grup arkadaşlarıyla çalışmak için kullanmışlardır.

5. Fen, Türkçe ve Sosyal Bilimler alanlarında proje gruplarına katılan öğrencilere aralık ayında ön-testler uygulanarak, proje tabanlı öğrenme sürecine başlanıımıştır. Öğrenciler toplam 11 grup oluşturmuşlardır (42 kişi). Bazı gruplar iki proje yapmak istemişlerdir ve bu şekilde toplam 16 proje çalışması yapılmıştır. Bu projelerden yedisi Fen Bilimleri, altısı Türkçe ve üçü de Sosyal bilgiler projeleri olmuştur.

6. Projenin çalışma sürecinde, proje tabanlı öğrenmenin aşamaları göz önünde bulundurularak adım adım ilerlenmiştir. Bu aşamalar şunlardır: konuyu belirleme ve grupları organize etme, proje planı oluşturma, projeyi uygulama, sunuyu planlama, sunuyu yapma. Bu süreçte öğrencilerin araştırma yapmaları, kendi problemlerini belirlemeleri, kendi çalışma süreçlerini yönlendirmeleri kısacası özerklikleri desteklenmiştir.

7. Proje tabanlı öğrenme süreci toplam altı ay sürmüştür. Bu süreç şu şekilde ilerlemiştir: Proje konusu için araştırma yapılması, proje konularının belirlenmesi ve proje öneri formunun sunulması, projelerin yapııması, proje sonuç raporlarının yazılması, projelerin bilim şenliği ile tanıtılmasıdır. 
6. Proje çalışma sürecinde, araştırmacılar dışında öğrencilere rehberlik etmek amacıyla Fen, Türkçe ve Sosyal Bilgiler öğretmen adaylarından her grup için birer öğretmen adayı görevlendirilmiştir. Böylece öğretmen adaylarına bu konuda tecrübe kazanma imkânı verilmiştir.

7. Bilim şenliği sonrasında öğrencilere son-testler uygulanmıştır.

\section{BULGULAR}

Bulgular bölümünde detaylı istatistik çalışmalarına yer verilmiştir.

\section{Akademik Öz-Yeterlik ve Akademik Motivasyon ölçeklerinin Doğrulayıcı Faktör analizi (DFA)çalışması}

AÖYÖ ve AMÖ çalışma grubuna uygulanmadan önce DFA yapılmıştır.

\section{Akademik Öz-Yeterlik Ölçeği}

Ölçeğin Doğrulayıcı Faktör Analizi için 7. sınıfta öğrenim gören 242 öğrenciye ölçek uygulanmıştır. Elde edilen verilerin öncelikle tek değişkenli ve çok değişkenli normalliği ve uç değerleri kontrol edilmiştir. Bu süreçte çarpıklık ve basıklık değerlerinin çok yüksek olduğu belirlenen 12, 19 ve 20. maddeler ölçekten çıkarılmıştır. Bu doğrultuda sadece 1 maddesi kalan (21. madde) "eğitimin kalitesi" alt boyutunun kullanılmamasına karar verilerek iki alt boyutlu olarak ölçeğe LISREL 8.80 (Jöreskog ve Sörbom, 2006) programı kullanılarak Doğrulayıcı Faktör Analizi yapılmıştır. Böylece 17 maddelik ölçeğin iki faktörlü yapısı maximum likelihood metodu kullanılarak test edilmiştir. Analizde 11. maddenin ölçeğin diğer maddeleriyle yüksek korelasyon verdiği belirlenmiş ve 11. maddenin de çıkarılması gerekmiştir. Analiz sonuçlarında elde edilen uyum katsayıları Tablo 1'de verilmiştir. Bu şekilde ölçeğin iki boyutlu (yetenek ve ortam boyutu) ve 16 maddeden (10 madde yetenek boyutu, 6 madde ortam boyutu) oluşan formunun uygun olduğu belirlenerek çalışmada kullanılmıştır.

Elde edilen verilerin öncelikle tek değişkenli ve çok değişkenli normalliği ve uç değerleri kontrol edilmiştir. Bu süreçte çarpıklık ve basıklık değerlerinin çok yüksek olduğu belirlenen 12, 19 ve 20. maddeler ölçekten çıkarılmıştır. Bu doğrultuda sadece 1 maddesi kalan (21. madde) "eğitimin kalitesi" alt boyutunun kullanılmamasına karar verilerek iki alt boyutlu olarak ölçeğe LISREL 8.80 (Jöreskog ve Sörbom, 2006) programı kullanılarak Doğrulayıcı Faktör Analizi yapılmıştır. Böylece 17 maddelik ölçeğin iki faktörlü yapısı maximum likelihood metodu kullanılarak test edilmiştir. Analizde 11. maddenin ölçeğin diğer maddeleriyle yüksek korelasyon verdiği belirlenmiş ve 11. maddenin de çıkarılması gerekmiştir. Analiz sonuçlarında elde edilen uyum katsayıları Tablo 1'de verilmiştir. Bu şekilde ölçeğin iki boyutlu (yetenek ve ortam boyutu) ve 16 maddeden (10 madde yetenek boyutu, 6 madde ortam boyutu) oluşan formunun uygun olduğu belirlenerek çalışmada kullanılmıştır. 
Proje Tabanlı Öğrenme Sürecinin Ortaokul Öğrencilerinin Akademik Öz-Yeterlikleri Ve Motivasyonları Üzerine Etkisinin incelenmesi

Tablo 1: Akademik Öz-Yeterlik Ölçeği Uyum Katsayıları

\begin{tabular}{llcccccc}
\hline Uyum Ölçüsü & RMSEA & $\boldsymbol{X}^{2}$ & $\boldsymbol{X}^{2} / \mathbf{d f}$ & NFI & AGFI & CFI & GFI \\
\hline Değeri & 0.073 & 237.01 & 2.30 & 0.90 & 0.86 & 0.94 & 0.89 \\
\hline
\end{tabular}

2. Akademik Motivasyon Ölçeği: Ölçeğin Doğrulayıcı Faktör Analizi için 7. sınıfta okuyan 242 öğrenciye ölçek uygulanmıştır. Elde edilen verilerin öncelikle tek değişkenli ve çok değişkenli normalliği ve uç değerleri kontrol edilmiştir. Daha sonra LISREL 8.80 (Jöreskog ve Sörbom, 2006) programı kullanılarak Doğrulayıcı Faktör Analizi yapılmıştır. Analizde maximum likelihood metodu kullanılarak ölçeğin 7. sınıflar da kullanılıp kullanılmayacağı tespit edilmiştir. Analiz sonucunda ölçeğin çalışmada kullanılabileceği belirlenmiştir. Uyum katsayıları Tablo 2'de belirtilmiştir.

Tablo 2: Akademik Motivasyon Ölçeği Uyum Katsayıları

\begin{tabular}{llllllll}
\hline Uyum Ölçüsü & RMSEA & $\boldsymbol{X}^{2}$ & $\boldsymbol{X}^{2} / \mathrm{df}$ & NFI & AGFI & CFI & GFI \\
\hline Değeri & 0.052 & 78.72 & 1.64 & 0.90 & 0.92 & 0.95 & 0.95 \\
\hline
\end{tabular}

Proje tabanlı öğrenme sürecinin öğrencilerin akademik öz-yeterlik ve akademik motivasyon düzeylerine etkisi

Çalışmanın bu temel amacı için ön test ve son test olarak uygulanan Akademik ÖzYeterlik ve Akademik Motivasyon Ölçeği verileri SPSS paket programı kullanılarak analiz edilmiştir. Ölçek verileri normal dağılım göstermemektedir. Bu nedenle nonparametrik testlerden Wilcoxon işaretli sıralar testi kullanılmıştır.

"Yetenek" ve "Ortam" şeklinde iki alt boyuttan oluşan Akademik Öz-Yeterlik Ölçeğinden elde edilen veriler Tablo 3'de belirtilmiştir.

Tablo 3: Akademik Öz-yeterlik Ölçeği Yetenek ve Ortam Alt Boyutu Ön Test- Son Test Analiz Sonuçları

\begin{tabular}{|c|c|c|c|c|c|c|}
\hline & Son Test-Ön Test & $\mathbf{N}$ & Sıra Ortalaması & Sıra toplamı & $\bar{Z}$ & $p$ \\
\hline \multirow[t]{3}{*}{ Yetenek } & Negatif sıra & 15 & 19,30 & 289,50 & \multirow[t]{3}{*}{,$- 685^{*}$} & \multirow[t]{3}{*}{,493 } \\
\hline & Pozitif sıra & 21 & 17,93 & 376,50 & & \\
\hline & Eşit & 6 & - & - & & \\
\hline \multirow[t]{3}{*}{$\overline{\text { Ortam }}$} & Negatif sıra & 17 & 19,44 & 330,50 & \multirow[t]{3}{*}{,$- 568^{* *}$} & \multirow[t]{3}{*}{,570 } \\
\hline & Pozitif sıra & 17 & 15,56 & 264,50 & & \\
\hline & Eşit & 8 & - & - & & \\
\hline
\end{tabular}

*Negatif sıralar temeline dayalı

**Pozitif sıralar temeline dayalı

Tablo 3 incelendiğinde, proje çalışmasına katılan öğrencilerin kendi yeteneklerine ve bulundukları okul ortamlarına yönelik olan güvenlerinde bir değişme meydana gelmediği görülmektedir. Bu doğrultuda genel olarak öğrencilerin akademik öz-yeterliklerinde bir değişme meydana gelmemiştir.

Akademik Motivayon Ölçeği alt boyutlarından oluşan "özdeşleşmiş dışsal motivasyon", "motivasyonsuzluk", "içe yansıtılmış dışsal motivasyon", "içsel motivasyon" şeklinde dört alt boyuttan elde edilen veriler tablo 4 'te verilmektedir. 
Tablo 4: Akademik Motivasyon Ölçeği alt boyutlarına yönelik ön test- son test analiz sonuçları

\begin{tabular}{|c|c|c|c|c|c|c|}
\hline & $\begin{array}{l}\text { Son Test-Ön } \\
\text { Test }\end{array}$ & $\mathbf{N}$ & $\begin{array}{l}\text { Sıra } \\
\text { Ortalaması }\end{array}$ & $\begin{array}{l}\text { Sıra } \\
\text { toplamı }\end{array}$ & $\mathrm{Z}$ & $\mathbf{p}$ \\
\hline \multirow{3}{*}{$\begin{array}{l}\text { Özdeşleşmiş Dışsal } \\
\text { Motivasyon }\end{array}$} & Negatif sıra & 2 & 1,50 & 3,00 & \multirow{3}{*}{$\begin{array}{l}- \\
1,342 * *\end{array}$} & \multirow[t]{3}{*}{180} \\
\hline & Pozitif sıra & 0 & 00 & 00 & & \\
\hline & Eşit & 40 & - & - & & \\
\hline \multirow{3}{*}{ Motivasyonsuzluk } & Negatif sıra & 8 & 6,63 & 53,00 & \multirow[t]{3}{*}{,$- 531 * *$} & \multirow[t]{3}{*}{,596 } \\
\hline & Pozitif sıra & 5 & 7,60 & 38,00 & & \\
\hline & Eşit & 29 & - & - & & \\
\hline \multirow{3}{*}{$\begin{array}{l}\text { İçe Yansıtılmış } \\
\text { Dışsal Motivasyon }\end{array}$} & Negatif sıra & 5 & 6,30 & 31,50 & \multirow[t]{3}{*}{,$- 630^{*}$} & \multirow[t]{3}{*}{, 529} \\
\hline & Pozitif sıra & 7 & 6,64 & 46,50 & & \\
\hline & Eşit & 30 & - & - & & \\
\hline \multirow{3}{*}{ İçsel Motivasyon } & Negatif sıra & 0 & 00 & 00 & \multirow[t]{3}{*}{$-2,264^{*}$} & ,024 \\
\hline & Pozitif sıra & 6 & 3,50 & 21,00 & & \multirow[t]{2}{*}{$* * *$} \\
\hline & Eşit & 36 & - & - & & \\
\hline
\end{tabular}

Tablo 4 incelendiğinde, proje çalışmasına katılan öğrencilerin yaptığı davranışın önemli olduğunu düşünerek kendisiyle özdeşleştirdiği için yapmasına yönelik olan özdeşleşmiş dışsal motivasyonlarında ve motivasyonsuzluk düzeylerinde bir değişme meydana gelmediği görülmektedir. Ayrıca proje çalışmasına katılan öğrencilerin içsel baskılarından dolayı ortaya çıkan davranışlarını belirten içe yansıtılmış dışsal motivasyon düzeylerinde de bir değişme meydana gelmemiştir.

Bu bulguların yanında proje çalışmasına katılan öğrencilerin, proje çalışmaları öncesi ve sonrası içsel motivasyon düzeylerinde istatistiki olarak anlamlı bir fark olduğu görülmektedir. Puanların sıra ortalamalarına bakıldığında gözlenen bu farkın pozitif sıralar yani son test lehine olduğu anlaşılmaktadır. Dolayısıyla bu çalışmada proje çalışmalarının öğrencilerin içsel motivasyonlarını artırdığı söylenebilir. Genel olarak bakıldığında çalışmada, proje çalışmaları öğrencileri sadece içsel olarak motive etmiştir.

\section{TARTIŞMA VE SONUÇ}

Proje tabanlı öğrenme sürecine uygun olarak yapılan proje çalışmalarının, ortaokul öğrencilerinin akademik öz-yeterliklerine ve akademik motivasyonlarına katkısının belirlenmeye çalışıldığı bu çalışmada; proje çalışmalarına katılan öğrencilerin çalışma sonucuna kendi yeteneklerine ve bulundukları okul ortamına yönelik öz-yeterliklerinde bir değişme meydana gelmemiştir. Bandura (1977), performans başarılarının yeterlik üzerine etkisi olduğunu belirterek, tekrarlanan başarı durumlarının yeterliği artırdığını, başarısızlık durumlarının da azalttığını ifade etmiştir. Bu proje çalışmasına katılan öğrencilerin ortaokul seviyesinde olmaları ve çoğunun ilk kez proje çalışması yaptığı göz önünde bulundurulduğunda öğrencilerin kendi yeteneklerine ve okul çevrelerine olan güven düzeylerinde bir değişme meydana gelmemesinin bu durumdan kaynaklanabileceği fakat öğrencilerin küçük yaşlarda edindikleri proje çalışmaları gibi tecrübe ve başarıların ilerleyen yıllardaki öz-yeterliklerinin gelişim sürecine katkıda bulunacağı düşünülmektedir. Ayrıca yapılan çalışmalar öğrencilerin, 
sınıf seviyeleri arttıkça öz-yeterliklerinin de arttığını göstermektedir (Shell, Colvin ve Bruning, 1995; Zimmerman ve Martinez-Pons, 1990). Bunun yanında Aydın (2012), yaptığı çalışmada proje tabanlı öğrenme sürecinin üniversite öğrencilerinin öz-yeterliklerini artırdığını belirlemiştir. Literatürde belirlenen bu durum yapılan bu çalışmada öğrencilerin sınıf düzeylerinin küçük olmasının (7. sınıf) öz-yeterliklerinin artmaması açısından bir sebep olabileceğini, öğrencilerin öz-yeterlik düzeylerinin ilerleyen sınıflarda daha başarılı ve olumlu tecrübeler edindikleri zaman artabileceğini düşündürmüştür.

Çalışmadan elde edilen sonuçlara göre öğrencilerin, akademik motivasyon düzeylerine bakıldığında; özdeşleşmiş dışsal motivasyon, içe yansıtılmış dışsal motivasyon ve motivasyonsuzluk düzeylerinde bir farklılık meydana gelmediği görülmektedir. Öğrencilerin sadece içsel motivasyon düzeylerinde bir farklılık meydana gelmiştir. Bu durum proje çalışmalarının öğrencileri içsel olarak motive ettiklerini yani öğrencilerin kendi istedikleri için çalıştıklarını göstermektedir. Lam, Cheng ve Ma (2009), öğrencilerin içsel motivasyonunu artıran öğretim uygulamalarının öğrencilere sadece kavramsal destek sağlamayı değil, aynı zamanda yararlı ve tatmin edici öğretmen-öğrenci ilişkisi de içerdiğini belirtmiştir. Bu açıdan proje çalışmaları öğretmenin etkili rehberliğinde öğrencilerin içsel motivasyonunu artıracaktır. Ayrıca Toci (2000) ortaokul öğrencileriyle yaptığı çalışmada, teknoloji destekli proje tabanlı öğrenme sürecinin öğrencilerin içsel motivasyonlarını artırmada etkili olduğunu belirlemiştir. Günümüzde proje tabanlı öğrenme sürecinde artık öğrenciler projelerinin gerek araştırma sürecinde gerekse tanıtımlarında teknolojiden yararlanmaktadırlar. Bell (2010) proje tabanlı öğrenmede çocukların gerçek dünyadaki problemleri; sorgulayarak, öğrenmelerini planlayarak, araştırmalarını organize ederek ve öğrenme stratejilerini kullanarak çözdüklerini ve öğrenmeye motive edici bu yaklaşımla öğrencilerin kendilerini geliştirdiklerini, gelecekleri için güçlü temeller oluşturduklarını belirtmiştir. Petersen (2008)'in çalışması da, bu görüşü destekler niteliktedir. Çalışmada öğrenciler, proje çalışmalarının ilgi çekici ve motive edici olduğunu ifade etmişlerdir.

Ayrıca yapılan çalışmalar gerek okulda gerekse ev ortamında öğrencilerin özerkliklerinin desteklendiği zaman yani kendi seçimlerini yapmalarına, kendi problemlerini çözmelerine ve kendilerini ifade etmelerine fırsat verildiği zaman temel psikolojik ihtiyaçlarının karşılandığını ve böylece içsel olarak motive olduklarını göstermektedir (Froiland, Oros, Smith ve Hirchert 2012; Niemiec ve Ryan, 2009). Bu proje çalışmasında öğrencilerin özerklikleri desteklenmiş, görüşleri dinlenmiş, kendi proje konularını seçmeleri sağlanmış ve kendi problemlerini çözebilmeleri için onlara fırsatlar verilmiştir. Bu nedenle çalışmada öğrencilerin içsel motivasyon düzeylerinin arttığı görülmektedir.

Dışsal motivasyona bakıldığındada, öğrencilerin eğitimsel görevleri elde edeceği sonuç için (ödül ya da takdir görme vb.) yaptıkları oysa içsel olarak motive olanların ilgi duydukları ve hoşlandıkları için yaptıkları görülmektedir (Deci ve Ryan, 1980; 1985). Eğitim sürecine öğrencilerin içsel olarak motive olmuş bir şekilde katılmaları eğitimciler tarafından istenen bir davranıştır. Ryan ve Deci (2000), içsel motivasyonun öğrenmeye ve yaratıcılığa etkisi olduğunu belirtmektedir. Oysa dışsal olarak motive olan öğrenciler ilgisiz, zoruna gittiğini gösteren, karşı çıkan davranışlar sergileyebilir ya da görevin önemi ve faydasına karşı isteksiz bir tutum 
sergileyebilirler. Ayrıca davranışlarından elde ettikleri başarıları ailesine, arkadaşlarına, çevresine göstermek için yaparlar (Ryan ve Deci, 2000). Belki de bu nedenle içsel olarak motive olan öğrenciler dışsal olarak motive olan öğrencilere göre daha başarılıdırlar. Lepper, Corpus ve Iyengar (2005) çalışmalarında, dışsal motivasyonun başarı ile negatif ilişkili olduğunu belirlemişlerdir. Incelenen tüm bu çalışmalar doğrultusunda bu çalışmada, proje tabanlı öğrenme sürecinin öğrencilerin içsel motivasyon düzeylerini artırdığının tespit edilmesi önemli ve sevindirici bir sonuç olmuştur. Bu durum öğretmenlerin, öğrencilerinin derse karşı içsel olarak motive olmuş bir şekilde katılmalarını sağlamaları için derslerinde proje çalışmaları yapabileceklerini göstermektedir.

\section{KAYNAKÇA}

Akbaba, S. (2006). Eğitimde motivasyon. Atatürk Üniversitesi Kazım Karabekir Eğitim Fakültesi Dergisi, $13,343-361$.

Aktepe, V. \& Aktepe, L. (2009). Fen ve Teknoloji öğretiminde kullanılan öğretim yöntemlerine ilişkin öğrenci görüşleri: Kırşehir bilsem örneği. Ahi Evran Üniversitesi Kırşehir Eğitim Fakültesi Dergisi, 10(1), 69-80.

Aydın, S. \& Yel, M. (2013). Proje tabanlı öğrenme ortamlarının biyoloji öğretmen adaylarının özdüzenleme seviyeleri ve öz-yeterlik inançları üzerine etkisi. Electronic Turkish Studies, 8(12), 95107.

Bandura, A. (1977). Self-efficacy: toward a unifying theory of behavioral change. Psychological review, 84(2), 191-215.

Bandura, A. (1997). Self efficacy: The exercise of control. New York: W. H. Freeman and Company.

Bandura, A. and Adams, N. E. (1977). Analysis of self-efficacytheory of behavioral change. Cognitive Therapy and Research, 1(4), 287-310.

Bell, S. (2010). Project-based learning for the 21st century: Skills for the future. The Clearing House, 83(2), 39-43.

Blumenfeld, P. C.,Soloway, E., Marx, R. W., Krajcik, J. S., Guzdial, M., and Palincsar, A. (1991). Motivating project-based learning: sustaining the doing, supporting the learning. Educational Psychologist, 26(3\&4), 369-398.

Büyüköztürk, Ş., Kılıç Çakmak, E., Akgün, Ö. E., Karadeniz, ş. \& Demirel, F. (2012). Bilimsel Araştırma Yöntemleri. Ankara: Pegem Akademi Yayıncilık.

Çiftçi, S. (2006).Sosyal bilgiler öğretiminde proje tabanlı öğrenmenin öğrencilerin akademik risk alma düzeylerine, problem çözme becerilerine, erişilerine, kalıcılığa ve tutumlarına etkisi, (Doktora Tezi), Selçuk Üniversitesi, Konya.

Deci, E. L. and Ryan, R. M. (1980). The empirical exploration of intrinsic motivational processes. In L. Berkowitz (Ed.), Advances in experimental social psychology (Vol. 13, pp. 39-80). New York: Academic.

Deci, E. L. and Ryan, R. M. (1985). Intrinsic motivation and self-determination in human behavior. New York: Plenum Press.

Erdem, M. (2002). Proje tabanlı öğrenme. Hacettepe Üniversitesi Eğitim Fakültesi Dergisi, 22, 172-179.

Fleming, D. S. (2000). A teacher's guide to project-based learning. Washington: Office of Educational Research and Improvement. ERIC Database, ED469734.

Fortier, M. S.,Vallerand, R. J. and Guay, F. (1995). Academic motivation and school performance: Toward a structural model. Contemporary Educational Psychology, 20, 257-274. 
Froiland, J. M., Oros, E., Smith, L. and Hirchert, T. (2012). Intrinsic motivation to learn: The nexus between psychological health and academic success. Contemporary School Psychology: Formerly" The California School Psychologist", 16(1), 91-100.

Gerlach, D. L. (2008). Project-based learning as a facilitator of self-regulation in a middle school curriculum. Unpublished Doctoral Dissertation, University of Pittsburgh.

Gottfried, A.E. (1990). Academic intrinsic motivation in young elementary school children. Journal of Educational Psychology. 82(3), 525- 538.

Helle, L.,Tynjala, P.and Olkinuora, E. (2006). Project-based learning in post-secondary education-theory, practice and rubbersling shots. Higher Education, 51, 287-314.

Jöreskog, K. G., and Sörbom, D. (2006). LISREL 8.80 for Windows [Computer Software]. Lincolnwood, IL: Scientific Software International, Inc.

Kara, A. (2008). İlköğretim birinci kademede eğitimde motivasyon ölçeğinin Türkçeye uyarlanması. Ege Eğitim Dergisi, 9(2). 59-78.

Korkmaz, H., and Kaptan, F. (2001). Fen eğitiminde proje tabanlı öğrenme yaklaşımı. Hacettepe Üniversitesi Eğitim Fakültesi Dergisi, 20, 193-200.

Krajcik J. S.,Czerniak C. M. and Berger C. (1999). Teaching Children Science: A Project-Based Approach, Boston, MA: McGraw-Hill.

Lam, S. F.,Cheng, R. W. Y. and Ma, W. Y. (2009). Teacher and student intrinsic motivation in projectbased learning. Instructional Science, 37(6), 565-578.

Lepper, M. R., Corpus, J. H. and Iyengar, S. S. (2005). Intrinsic and extrinsic motivational orientations in the classroom: age differences and academic correlates. Journal of educational psychology, 97(2), 184.

Mills, N. (2009). A guide du routard simulation: Increasing self-efficacy in the standards through projectbased learning. Foreign Language Annals, 42 (4). 607-639.

Niemiec, C. P. and Ryan, R. M. (2009). Autonomy, competence, and relatedness in the classroom: Applying self-determination theory to educational practice. Theory and Research in Education, 7(2), 133-144.

Önen, F., Mertoğlu, H., Saka, M. and Gürdal, A. (2010). Hizmet içi eğitimin öğretmenlerin proje ve proje tabanlı öğrenmeye ilişkin bilgilerine ve proje yapma yeterliklerine etkisi: Öpyep örneği. Ahi Evran Üniversitesi Kırşehir Eğitim Fakültesi Dergisi, 11(1). 137-158.

Öncü, H. (2012). Akademik Özyeterlik Ölçeğinin Türkçe'ye Uyarlanması. Ahi Evran Üniversitesi Kırşehir Eğitim Fakültesi Dergisi, 13(1), 183-206.

Petersen, C. (2008). Project-based learning through the eyes of teachers and students: investigating opinions of PBL in adult ESL. Unpublished Master of Arts Thesis, University of Victoria, Canada.

Ryan, R. M. and Deci, E. L. (2000). Intrinsic and extrinsic motivations: Classic definitions and new directions. Contemporary Educational Psychology, 25, 54-67.

Schunk, D. H. and Meece, J. L. (2006). Self-efficacy development in adolescence. In F. Pajaresand T. Urdan (Eds.), Self-Efficacy Beliefs of Adolescents (pp. 71-96). The United States of America: Information Age.

Shell, D. F.,Colvin, C. and Bruning, R. H. (1995). Self-efficacy, attribution, and out come expectancy mechanisms in reading and writing achievement: Grade-level and achievement-level differences. Journal of Educational Psychology, 87(3), 386-398.

Sünbül, A. M. (2007). Öğretim ilke ve yöntemleri. Konya: Çizgi Kitabevi Yayınları.

Thomas, J. (2000). A review of research on project-based learning. Web: http://www.bobpearlman.org/BestPractices/PBL Research.pdf25.03.2010'da alınmıştır. 
Toci, M. J. (2000). The effect of a technology-supported, project-based learning environment on intrinsic and extrinsic motivational orientation. Unpublished PhD Thesis, The Pennsylvania University, Philadelphia.

Tuan, H.L, Chin, C.C. and Shieh, S.H. (2005). The development of a questionnaire to measure students' motivation towards science learning. International Journal of Science Education, 27(6), 639-654.

Zimmerman, B.J. (1989). A social cognitive view of self-regulated academic learning. Journal of Educational Pyschology, 81(3), 329-339.

Zimmerman, B. J. and Martinez-Pons, M. (1990). Student differences in self-regulated learning: Relating grade, sex, and giftedness to self-efficacy and strategy use. Journal of educational Psychology, 82(1), 51-59. 


\section{SUMMARY}

The main purpose of this project that is supported by TÜBITAK was to provide opportunities for successful and enterprising middle school students in Kars city center to create and introduce their own projects in accordance with their own interests and abilities, and to determine the effects of this opportunity on their academic self-efficacy and academic motivation levels. It was decided to conduct this study with 7th grade students with suggestion of the Provincial Education Directorate and because the study process was long and 8th grade students generally prepared for TEOG national examination. Prior to the study, this project was presented to 7 th grade students and 42 students who wished to participate to this study voluntarily were included to the study. In this study, single group pre test-post test experimental design was used. Additionally, data collection methods that were used in this study were Academic Self-Efficacy Scale and Academic Motivation Scale. These scales were applied to the study group as pre test and post test.

Experimental study lasted six months. Students made project studies as creating groups in Science, Turkish and Social Sciences fields. This study was conducted in the view of project based learning phases. In project study process, one teacher candidate per each group was assigned to groups from Science, Turkish and Social Sciences fields to guide students in addition to researchers. At the end of the study, students were given opportunity to present their projects in science festival.

As a result of this study, a change was not observed in self-efficacy levels toward the school environment that they were present and confidence in their own abilities of the students that participated to the study. It was thought that the reason that a change in students' self-abilities and trust feeling to their school environment was not observed might be attributed to the fact that the students who participated to this study were secondary school students and majority of them made their first projects, therefore experience and success that they gained with project studies in their early years would make contributions to their self-sufficiency development process for the future. The previously conducted studies show that students' self-efficacy levels increase with their grade levels (Shell, Colvin and Bruning, 1995; Zimmerman and Martinez-Pons, 1990). Therefore, low level of student grade levels (7th grade) in this study could be attributed to that self-efficacy levels of the students in this study did not rise, however self-efficacy levels of the students could increase when they would gain successes and positive experiences in their future years.

According to study results, it could be seen that a change in identified external motivation, introjected external motivation and amotivation levels did not occur in the analysis of students' academic motivation levels. A change was observed for only intrinsic motivation level. This condition showed that project studies motivated students for only internally, in other words, students studied only because they wanted to study. Lam, Cheng and Ma (2009) showed that the learning applications that increased students' intrinsic motivations not only contribute students about conceptual support but also they include beneficial and satisfactory teacher-student relationship. In this framework, project studies can increase students' intrinsic motivation levels with an effective teacher guidance.

Additionally, the previously conducted studies show that students' basic psychological needs are met when students' freedom is supported in both school and home environment, i.e. they are allowed to make their own choices, to solve their own problems and to be given opportunities for self-expression, so that they are internally motivated (Froiland, Oros, Smith and Hirchert 2012; Niemiec and Ryan, 2009). During this study, students' freedom was supported, their opinions were listened, and they were given opportunities to select their own projects and to solve their own problems. Therefore, increase in students' internal motivation levels was observed.

Generally, determination of that project based learning process increases students' intrinsic motivation levels is an important and promising conclusion in this study. This condition shows that teachers can organize project studies in their lectures to have their students participated to courses as intrinsic motivated. 